\title{
PATIENT-BASED DECISION SUPPORT SYSTEMS: A CALL TO ACTION
}

\author{
Matthew R. Kisow, M. NSABP Foundation, Inc., matt.kisow@nsabp.org \\ Janusz Ochota, M. Robert Morris University, jxost9@mail.rmu.edu
}

\begin{abstract}
Sixty-six percent of Internet users in the United States in 2007 used a search engine to research health information to help themselves make health-related decisions. As a result physicians are increasingly compelled to defend their diagnoses and clarify the information their patients have found. The researchers propose the development of patient-oriented decision support systems by which laypersons can retrieve medical information. Through utilizing semi structured decision support systems that incorporate the latest standards in evidence-based medicine patients and caregivers can receive current, accurate and appropriate information. The exigencies of managed care have increased time pressures among most medical practices. Yet addressing concerns based on potentially misleading or harmful internet based information has garnered an increasing portion of practitioners' time and mandates urgent attention.
\end{abstract}

Keywords: patient-oriented decision support system, evidence-based medicine, informed decision

\section{INTRODUCTION}

Decision Support Systems (DSS) are computer-based information systems designed to assist users to make decisions in semi-structured situations [20, 29]. To support the decisions of either the patient or primary decision-maker, a patient-based DSS should be designed to mitigate the risk of misleading and potentially dangerous information [1], providing the patient with current and robust information to make an informed decision. To support the decisions of either the patient or primary decision-maker, a patient-based DSS should be interactive, flexible, and adaptable [29]. It should utilize the latest standards in evidence-based medicine which, according to Eddy [7], is where the treatment and care of patients "should be based, to the greatest extent possible, on evidence".

The Pew Internet and American Life Project has revealed a paradigm shift among Internet-connected users. The Internet is now typically used to support decisions related to all major life moments [11, 12, 13, 19, 23]. A current lack of available patient-based tools is causing patients and primary decision makers to go online to search for health information using popular search engines. Sixtysix percent of Internet users in the United States in 2007 used a search engine to research health information for

themselves or to help others make a health-related decision. Studies have revealed that Internet users seldom check the date and source of the information they consume [1,13]. Search engines are the typical starting points for most Internet users looking for health information online [11, 13].

Physicians with patients who have researched their symptoms on the Internet are either compelled, from an ethical standpoint, to defend their diagnosis or clarify the information their patients have found, consuming more of the physician's time [1,30]. In many cases, patients become distressed and overwhelmed because the information they are reading is full of misleading and potentially dangerous information that they do not know how to critically evaluate or interpret $[1,4,9,31]$.

This study proposes the development of a patient-based DSS by which patients can retrieve the latest lay medical information relating to the most common diseases, their diagnosis and treatment. Through informed decision making, utilizing semi-structured DSS and the latest standards in evidence-based medicine, patients and caregivers can receive the most current information available to share with their physician. Addressing patients' concerns engendered by potentially misleading or harmful internet based information has garnered an increasing portion of practitioners' time. Yet the time pressures of managed care make such efforts untenable. The American Medical Association (AMA) notes [2], patients are predicted to receive less attention from physicians due to declining reimbursements and the exigencies of satisfying insurer contracts. The AMA and other research seems to predict that an impact of changes in physician practice arrangements will be that patients will take a more active role in medical decision-making, and physicians will increasingly be asked to discuss and justify decisions and diagnoses and address facts that patients do not understand $[1,2,30]$. 


\section{BACKGROUND}

Kommers \& Rainie [23] note that among Internet users who have dealt with personal illness, those aged 50-64 were more likely to report the internet's impact as crucial or important. Women were twice as likely as men to report it as well. The authors also note that $57 \%$ of those that have helped others deal with illness found the Internet to play some role, $28 \%$ a crucial or important role, and $31 \%$ a minor role [23]. Implications for health related websites include tailoring the information presented to a variety of education levels. Perhaps context sensitive help, allowing each user to tailor the information to their needs and obtain help with confusing terminology as needed would allow for broader appeal. Considering the growing population involved in Internet use over time, it seems that health related web sites have not modified sufficiently to increase their impact upon the individual user.

The Internet has matured to increase the ease at which information can be obtained while decreasing the complexity and knowledge required, for wider appeal. Popular medical websites have been developed for the layperson. Good information results in good choices, patients need good information and guidance to assist them in making the right choices for themselves or their loved ones. Another survey funded by Pew Internet \& American Life Project [12] reports that $64 \%$ of adults with chronic conditions use the Internet and are avid consumers of health related information [12, 13, 28]. Another survey conducted by Harris International in 2007 found that an estimated 180 million adults have used the Internet for this same purpose. They note that the percentage of adults seeking health information had increased from $52 \%$ in 2005 to $71 \%$ by the time of the survey in 2007 [17].

Chronic medical conditions tend to increase online health research. A 2008 study conducted by Fox notes that 59\% of patients found information online that led them to ask questions of their physician about their condition or to seek a second opinion [13]. This is a $31 \%$ increase when compared to a 2006 study conducted by Madden and Fox [24]. Those patients and primary decision-makers who are dealing with these types of conditions are more likely than other Internet users to engage in online health research. This group has also reported greater impacts from their health-related online research $[13,24]$.

A secondary analysis of the 2002 Kommers and Rainie [23] data set reveals additional information regarding the importance of education to the rated importance of the internet when dealing with personal illness. As indicated in Table 1, there were 302 respondents that had personally experienced a major illness within the last two years and rated the importance of the internet as they dealt with this event. Just $19 \%$ of those with a high school education, or less, rated the Internet as having high importance to their experience of illness while $30 \%$ of those with greater than high school education responded that the Internet was thus important.

The relationship between education and user ratings of the Internet's importance on their personal experience of illness, is supported with $97 \%$ confidence. Although the internet has become a ubiquitous presence and popular health related web sites are in abundance, it seems that such information remains better utilized by those with greater levels of education. Whereas finding information may have become easier, understanding medical and health related information may remain daunting to some as noted in their lower rating of the impact of this information. Implications for health related websites include tailoring the information presented to a variety of education levels. Perhaps context sensitive help, allowing each user to tailor the information to their needs and obtain help with confusing terminology as needed would allow for broader appeal. The original Kommers and Rainie study of 2002 [23] noted that overall, $26 \%$ of respondents reported that their use of the internet had a high level of importance to their personal experience of illness, which is little changed in 2005 [19], with $29 \%$ within the same category. Considering the growing population involved in Internet use over time, it seems that health related web sites have not modified sufficiently to increase their impact upon the individual user. Although there are now web sites designed for the layperson, it appears that there are many layers within that group not sufficiently addressed by information providers [1]. 
Table 1. Role of Education

In spite of the many web sites designed for the layperson, it appears that there are many information providers that do not sufficiently address this need. It is not feasible to educate the public in the critical evaluation of the information that is now available to them [1]. Patients and primary decision makers encounter search engines often designed to advertise drugs rather than to provide the knowledge that they seek [1]. While the abundance of popular health-related websites make finding information easy, understanding medical information remains daunting to many. A study conducted by Fox [12] indicates that health related research has resulted in the patient or primary decision-maker becoming overwhelmed $30 \%$, frustrated $31 \%$, confused $19 \%$ and or frightened $9 \%$. Researchers note that it is extremely difficult to differentiate the scientific information from the nonscientific claims, while raising ethical concerns for the potential misuse and misinformation widely available on the Internet $[1,14]$.

\section{INTERNET ADVERTISING}

Direct-to-consumer marketing of Food and Drug Administration (FDA) approved drugs is now commonplace. As a result of this targeted and direct marketing strategy a 2005 study noted that $40 \%$ of patients, as reported by physicians, have shown that their decision-making was influenced from this type of marketing. In $88 \%$ of these cases the patient did have the condition the drug was designed to treat, however, the majority of patients understood the benefits much better than they did the risks. The FDA has since revised these guidelines to increase consumer awareness of these risks. Physicians have further reported that $27 \%$ of patient visits have resulted in the identification of a new condition because of these advertisements [4, 31].

The Internet however is a different type of marketing tool. Search engines and websites using cookies, which are information files designed to track user activity, are targeting consumers based upon the types of searches they conduct [14, 25]. In 2009, fourteen complaints over direct marketing links on popular search engines led the FDA to crack down on this type of marketing [25]. Similarly in 2001 complaints to the Federal Trade Commission (FTC) stated that search engine results were based upon the amount of money a website owner was willing to pay these providers to direct Internet users to their sites. Laws aimed at stopping this practice now state that results with paid content must be clearly marked as paid for advertisements [16]. Although clearly marked, these results still appear at the top of

\begin{tabular}{|c|c|c|c|c|}
\hline \multicolumn{5}{|c|}{$\begin{array}{l}\text { Education and the Role of the Internet when dealing } \\
\text { with Illness. }\end{array}$} \\
\hline \multirow{2}{*}{\multicolumn{2}{|c|}{$\begin{array}{l}\text { Role of Internet } \\
\text { Dealing with Illness }\end{array}$}} & \multicolumn{2}{|c|}{ Education } & \multirow[t]{2}{*}{ Total } \\
\hline & & \begin{tabular}{|l|} 
High \\
School \\
or Less
\end{tabular} & $\begin{array}{l}\text { Coll } \\
\text { or } \mathrm{M}\end{array}$ & \\
\hline $\begin{array}{l}\text { High } \\
\text { Importance }\end{array}$ & $\begin{array}{c}\text { Web Count } \\
\% \text { of } \\
\text { Total }\end{array}$ & 12 & $\begin{array}{ll}63 \\
24.3 \%\end{array}$ & $\begin{array}{l}75 \\
28.6 \%\end{array}$ \\
\hline $\begin{array}{l}\text { Low } \\
\text { Importance }\end{array}$ & $\begin{array}{c}\text { Web Count } \\
\% \text { of } \\
\text { Total }\end{array}$ & $20.9 \%$ & $\begin{array}{l}168 \\
52.5 \%\end{array}$ & $\begin{array}{l}227 \\
73.4 \%\end{array}$ \\
\hline Total & $\begin{array}{l}\text { Count } \\
\% \text { of } \\
\text { Total }\end{array}$ & $\begin{array}{l}71 \\
27.2 \%\end{array}$ & $\begin{array}{l}231 \\
74.8 \%\end{array}$ & $\begin{array}{l}302 \\
100.0 \%\end{array}$ \\
\hline
\end{tabular}

search engine result lists where non savvy Internet users can click on them.

\section{THE INTERNET AND INFORMED DECISION MAKING}

For a growing number of medical decisions the best choice depends upon a holistic assessment of the effects of medical procedures. Patients cannot properly weigh the benefits and harms among available choices without examining all of the factors in light of their personal values and beliefs. Informed decision making occurs when the either patient or primary decision-maker fully understands and comprehends the disease or condition being addressed. This includes understanding the required treatment for the disease or condition along with its benefits, risks, limitations, alternatives and uncertainties [24, 11]. Once understood and weighed against personal values an informed decision can be made and appropriate treatment can begin [24, 27, 11]. Yet abundant, complex and easily available medical information of dubious credibility may obfuscate the decision-making process.

Uncertainties can easily be caused by misunderstood scientific information, adding to the burden of patients and their care providers. In today's consumer-oriented health care system patients desire choice and an active role in the decision-making process, and most patients need education to lessen their anxiety $[20,11]$. Yet the goal of informed consent is not easily facilitated through typical search-engine based results. 


\section{THE HUMAN ELEMENT}

The Internet has the potential to provide information to aid in the interaction and constructive dialogue between physicians and their patients [11, 29]. The traditional doctor and patient conversation remains a critical component of primary care. It is necessary to better inform patients' decisions about their treatment. However the exigencies of managed care and modern practice often leave inadequate time for effective interaction $[1,3,5,8]$. Thoughtful analysis of the many elements involved in any medical procedure coupled with the best information available and decision counseling is typically the best approach [1, 5, 8, 21].

Decision counselors are able to offer support, sensitivity and guidance to enable patients and decision-makers to make the "right choice" based upon their personal preferences. Decision counseling often exceeds and excels over impersonal decision aids. A 2002 study conducted by Kennedy, Sculpher, et al. [21] concluded that patients that had used decision aids had little or no impact on patient satisfaction unless they were used in union with decision counseling by a trained nurse or counselor [5, 10, 18, 21]. Patient and decision-maker participation, however, has increased as a result of these paper based and electronic decision aids [6, 10]. The Internet cannot function as a partner in medical-based decisions alone. The overwhelming benefit from human counseling is about the interaction and relationship between the patient and the counselor $[1,5,10,21]$.

Counselors should use current, unbiased and evidencebased research. The patient's knowledge, experience and expectations should inform the counselor's efforts. It is important for counselors to build partnerships, provide evidence including risks and uncertainties, present recommendations and check for understanding $[5,8]$.

\section{PATIENT-BASED DSS CHARACTERISTICS AND CAPABILITIES}

The objectives of any patient-based DSS are to assist non-physician stakeholders in acquiring knowledge to facilitate making informed decisions. By coupling DSS information with high-quality decision counseling patients may then be allowed to successfully weigh the benefits, risks and limitations among appropriate alternatives for care. Clinical informatics or DSS are computer software systems most typically designed to aid physician decision-making.
Expert systems make inferences in the same manner as a human expert by inferring solutions based on their own knowledge, and the collection of pertinent facts. Expert systems typically have their knowledge encapsulated in If...Then type rule sets where an inference engine will then pattern match relevant facts to the antecedent of the rule. Once a pattern is matched a conclusion will be generated or an action performed that then adds to the list of facts. Expert systems differ from conventional programming in that the problems they consider have no algorithmic solution [15]. Limitations of these systems are their lack of understanding of cause and effect relationships; they rely instead on empirical knowledge. A benefit, however, lies in their ability to include an explanation facility which can exhibit the inference chain of rules that were used to draw a conclusion or arrive at a diagnosis. Whereas the diagnostic criteria for a given diagnosis may be consistent, straightforward and evidenced-based; the effective recognition of relevant observable and unobservable symptoms is often elusive. Thus a patient based system should accept layman's terms when collecting facts and handle uncertainty concerning relevant observations.

DSS are typically defined as computer and software based systems designed to assist users in making decisions in semi-structured environments [22, 29]. These systems typically fail, however, because of the designer's failure to adequately examine the user's needs. Simple systems like dosing and reminder systems have shown great success in the improvement of process care [3]. A "patient-based" DSS should take what we have learned about clinical information and expert systems and apply that to the layperson. The system should be readily available to stakeholders of varying levels of education and experience use the same standards available in a clinical DSS.

\section{GUIDELINES FOR A MODEL OF PATIENT BASED DSS}

Research conducted by The Foundation for Informed Medical Decision Making (FIMDM) [10], a leading nonprofit organization dedicated to ensure that health care decisions are made with the active participation of fully informed patients, has shown that decision aids increase participation, decrease decisional conflict and indecision, and improve decision quality indicators when weighed against patient personal values $[5,8,10]$. Their research along with research conducted at the Center for Shared Decision Making at Dartmouth-Hitchcock Medical 
Center, [6] the pioneer of informed decision-making programs for their patients, has shown similar findings. Patient-based DSS to facilitate informed decisions should include the following characteristics:

1. Availability to all patients, and adaptability to different levels of education and experience in order to support the decision-making processes and styles of stakeholders.

2. Used in combination with traditional patient education such as pamphlets face-to-face and video along with high quality decision counseling that will enhance patients understanding of the risks, benefits, and uncertainties of different medical procedures.

3. Accomplish the goals mentioned in one and two, by supplying adequate resources so each patient has the same quality of care.

4. Enhance information delivery to patients by using traditional and rich-media based medical informatics systems.

5. Provide support for decision makers in a semi-structured environment by bringing together both human judgment and rich information.

6. Provide support for several interdependent or sequential health decisions at the same time.

7. Allow the patient or primary decisionmaker to model different medical situations weighing each against their personal values $[10,22,29]$.

8. Inform patients of DSS limitations and mission as educational tools, clearly disclaiming DSS as substitutes for physician based diagnosis and care.

Success can be measured by surveying the patients or primary decision-makers. Patients or primary decisionmakers that have undergone education and decision counseling would be surveyed prior to the medical procedure and post procedure.

\section{MEDICAL EXPERT SYSTEMS FOR PATIENT BASED DSS}

Medical expert systems historically have been designed to assist professionals working in a given field who may wish to have expert consultation for diagnosis or treatment. It is here suggested that existing expert systems can be modified and new systems created for the layperson in search of medical information based on their potential diagnosis. An expert system is a program that uses a knowledge base and inference procedures to solve problems that are in the domain of a human expert. In this manner an expert system can emulate the decision making capabilities of a human expert [15]. Expert systems are a branch of Artificial Intelligence using specialized knowledge that may be acquired from published research or directly from expert practitioners. They typically consist of both a knowledge base and an inference engine [15]. Expert systems are primarily rule based. The antecedents of rules can be matched against known facts entered by users. Conclusions are drawn by the inference engine based on the acquired knowledge as well as relevant facts gathered by the system user. Expert systems make inferences in the same manner as a human expert would infer solutions based on their own knowledge and pertinent facts. Expert systems frequently have their knowledge base encapsulated in If...Then type rules. The inference engine will then pattern match relevant facts to the antecedent of the rule. Once matched the conclusion will be generated and can perform an action or add to the list of facts. Expert systems differ from conventional programming in that the problems they consider have no algorithmic solution [15]. A limitation of expert systems is their lack of understanding of cause and effect relationships [15]. They rely instead on empirical knowledge. A benefit of expert systems lies in their ability to include an explanation facility which can exhibit a rule or chain of rules that were used to draw a particular conclusion.

\section{CONCLUSIONS}

There are numerous medical and health related websites available on the Internet. The challenging part for patients and primary decision-makers is finding one that has complete and accurate information. Navigating through advertisements, biased, incomplete and inaccurate information are challenges that all patients must face. The real power of this proposed patient-based DSS would be to provide high-quality information to patients, helping them alleviate the stress and anxiety they may feel when researching these medical issues adhoc on generally available search engines. The purpose of this system is to provide laypersons with diagnoses in response to observed problematic behaviors, described in 
commonly understood health related vocabulary. By giving these consumers reliable non biased medical information that is understood by the general population can be an asset to both physicians and patients alike.

Electronic platforms are not likely to replace a human counselor's capacity for guidance and sensitivity to the needs and desires of the patient in the near future. Using a combination of human counseling and computer based decision support is perhaps better, if not the preferred method of choice among patients for these types of decisions. Patient engagement and involvement are key and this seems to be the primary benefit of a patientbased DSS. However, affect and gesture as well as other rich sources of communication may be necessary to recognize and address the emotions and values of the patient. It will then be incumbent on the counselor to provide the human element beyond the computer's capability.

\section{REFERENCES}

1. Ahmad, F., Hudak, P., Bercovitz, K, Hollenberg, E. Levinson, W. (2006). Are physicians ready for patients with Internet-based health information. Journal of Medical Internet Research. 8(3).

2. American Medical Association, (2008). AMA health care trends. Retrieved on March 16, 2010 from http://www.ama-

assn.org/amal/pub/upload/mm/409/2008-trendschapt-8.pdf

3. Berger, A., (1999). Computerised decision support systems in primary care. British Medical Journal. 319(7220). p. 1281.

4. Berndt, E.R., (2005). To inform or persuade? Directto-consumer advertising of prescription drugs. The New England Journal of Medicine. 352(4). p. 327330.

5. Charles, C., Gafni, A., et al., (1997). Shared decision-making in the medical encounter: what does in mean? (or it takes at least two to tango). Elsevier Science, Ltd.. 44(5). p. 681-692.

6. Dartmouth-Hitchcock Medical Center, (2010). DHMC center for shared decision making. Retrieved on March 12, 2010 from http://www.dhmc.org/shared_decision_making.cfm.

7. Eddy, D., (2005). Evidence-based medicine: A unified approach . Health Affairs. 26(1). p. 9-17.

8. Epstein, R., Alper, B., et al., (2004). Communicating evidence for participatory decision making. Journal of the American Medical Association. p. 2359-2366.
9. Food and Drug Administration, (2005). Guidance for industry: brief summary: disclosing risk information in consumer-directed print advertisements. Retrieved on March 10, 2010 from http://www.fda.gov/cder/guidance/5669dft.doc.

10. The Foundation for Informed Medical Decision Making, (2009). The Foundation for Informed Medical Decision Making. Retrieved on March 12, 2010 from http://www.informedmedicaldecisions.org/.

11. Fox, S., (2006). Most Internet users start at a search engine when looking for health information online. Very few check the source and date of the information they find. The Pew Internet and American Life Project. Washington, D.C..

12. Fox, S., (2007). E-patients with a disability or chronic disease. Just half of adults with chronic conditions use the Internet; but once online, they are avid consumers of health information. The Pew Internet and American Life Project. Washington, D.C..

13. Fox, S., (2008). The engaged e-patient population, people turn to the internet for health information when the stakes are high and the connection fast. The Pew Internet and American Life Project. Washington, D.C..

14. Gaslin, M., Rubin, C., et al., (2008). Silver nasal sprays: misleading marketing. Ear, Nose \& Throat Journal. 87(4). p. 217-221.

15. Girratano, J., Riley, G., (1998). Expert systems principles and programming. Third Edition. PWS Publishing Company. Boston, MA.

16. Goh, D., Ang, R., (2003). Relevancy rankings: pay for performance search engines in the hot seat. Online Information Review. 27. p. 87-93.

17. The Harris Poll \#76, (2007). Harris poll show number of "cyberchondriacs" - adults who have ever gone online for health informations - increases to an estimated 180 million nationwide. Retrieved on February 6, $\quad 2010$ from http://www.harrisinteractive.com/harris_poll/index.a sp?PID=792.

18. Hersey, J., Matheson, J., et al., (1997). Consumer health informatics and patient decision-making. Agency for Health Care Policy and Research. 98N001.

19. Horrigan, J., Rainie, L., (2006). The Internet's growing role in life's major moments. The Pew Internet and American Life Project. Washington, D.C..

20. Johnson, J., Roberts, C., Cox, C.Reintgen, D., Levine, J., Parsons, M., (1996). Breast cancer 
patients' personality style, age, and treatment decision making.. Journal of Surgical Oncology. 63. p. 183-186.

21. Kennedy, A., Sculpher, M., Coulter, A., Dwyer, N., Rees, M., Abrams, K., Horsley, S., Cowley, D. Kidson, C., Kirwin, C., Naish, C., Stirrat, G., (2002). Effects of decision aids for menorrhagia on treatment choices, health outcomes and costs. . 288(21). p. 2701-2708.

22. Kimball, R., Reeves, L., (1998). The data warehouse lifecycle toolkit: Expert methods for designing, developing and deploying data warehouses with CD Rom. First Edition.. John Wiley and Sons, NY.

23. Kommers, N., Rainie, L., (2002). Use of the Internet at major life moments. The Pew Internet and American Life Project. Washington, D.C..

24. Madden, M., Fox, S., (2006). Finding answers online in sickness and in health. The Pew Internet and American Life Project. Washington, D.C..

25. Osborne, R., (2009). FDA on warpath for Google links. Nature Biotechnology. 29(5). p. 405.
26. Rimer, B., Briss, P., Zeller, P., Chan, E., Woolf, S., (2004). Informed decision making: what is its role in cancer screening.

27. Sheridan, S., Harris, R., et al., (2004). Shared decision making about screening and $\mathrm{c}$ hemoprevention. A suggested approach from their U.S. preventive service task force. American Journal of Preventive Medicine. 26. p. 56-66.

28. Taylor, H., (2002). Cyberchondriacs update. Retrieved on February 24, 2010 from http://www.harrisi.org/harris_poll/index.asp?PID=7 92.

29. Turban, E., Aronson, J., (1998). Decision support systems and intelligent systems. Fifth Edition. Prentice Hall, NJ.

30. Vasconcellos-Silva, P., Castiel, L., (2009). New selfcare technologies and the risk of self-diagnosis through the Internet. Pan American Journal of Public Health. 28(2). p. 172-175.

31. Weissman, J., Blumenthal, D., et al., (2004). Physicians report on patient encounters involving direct-to-consumer advertising. Health Affairs. W4. p. 219-233. 